\title{
An analytical model for the prediction of rip spacing in intermediate beaches
}

\author{
A VAlipour ${ }^{1, *}$ and A A Bidokhti ${ }^{2}$ \\ ${ }^{1}$ Department of Marine Science and Technology, Jouybar Branch, Islamic Azad University, \\ Jouybar 47r61-86131, Iran. \\ ${ }^{2}$ Institute of Geophysics, University of Tehran, Tehran, Iran. \\ *Corresponding author.e-mail: a.valipour@yahoo.com
}

MS received 29 September 2017; revised 12 January 2018; accepted 9 February 2018; published online 29 September 2018

Considering the diversity of rip currents based on the classification of Castelle et al. (2016), it is crucial to study the characteristics of each individual rip current type, which are classified based on different dominant controlling forces and physical driving mechanisms. In this study, an analytical model was presented to predict the spacing of channel rip currents $\left(S_{\text {rip }}\right)$ in intermediate beaches using the equations of continuity and momentum. Then, the analytical model predictions were compared with the results of numerical simulations calibrated with field studies of other researchers, that showed good agreements. The main results of this study showed that rip spacing was simultaneously related to the characteristics of wave and bed in the surf zone. In addition, it was shown that due to inevitable changes of the hydrodynamic and morphological conditions of rip channel in the beach, the parameter $H_{b 0} / h_{c}$ (where $H_{b 0}$ is the wave height before approaching the sand bar and $h_{c}$ is channel depth) is an important factor in predicting the rip current situation and the changes of the beach state with time.

Keywords. Rip currents; intermediate beaches; surf zone; beach state; sandbar.

\section{Introduction}

Rip currents are the most common features in the intermediate beaches that play an important role in surf zone morphology (Short and Brander 1999). Hence, understanding the characteristics of these currents is considered as an important step to estimate the beach state, the prediction of morphodynamic conditions governing the beach and generally control these dangerous currents for swimmers. One of these characteristics is the spacing which is alongshore distance between two adjacent channels (Holman et al. 2006). Different studies have been carried out on the rip spacing in which some show formation of regular spacing between the channels (Eliot 1973) and less related to the characteristics of waves (Whyte et al. 2005; Holman et al. 2006; Turner et al. 2007). While some other research studies show that the formation of spacing between channels is heavily dependent on the characteristics of waves and is sometimes irregular, semi-irregular and mixed (Symonds et al. 1997). Bowen (1969) presented an analytical model for the aforesaid currents and indicated that the bed perturbations led to the longshore changes of wave height and subsequent formation of rip currents. In most analytical models that ever have been presented for investigation of the conditions governing the morphology of rip channels, the linear stability analysis have been used. Hino (1974) was the 
first to use the linear stability analysis to solve this problem and found that the longshore spacing scale of rip channels was about four times the distance of the peak sandbar from the shoreline. Iwata (1976) used the laws of conservations of mass, momentum and wave action, including the radiation stress tensor to calculate rip current spacing as an eigen value of a vorticity equation and found that this spacing was related to the beach slope. Deigaard et al. (1999) applied a stability analysis method to study how the formation of rip channels spacing depended on the barred beach. The results of his studies showed that the rip currents spacing was of the same order as the distance from the shoreline to the bars. Falqués et al. (2000) used the linearized stability problem with an originally plane sloping beach and normal wave incidence in two cases with the fixed breaking line and variable one to solve the problem and concluded that the rip channels spacing was proportional to the width of the surf zone. Tiessen et al. (2010) also used the linear stability analysis to predict the natural development of crescentic bed patterns and rip channels. He found that changes in the pattern of bed lead to changes in conditions of waves and tide level. Osaisai (2013) developed an analytical theory for the wave-current interaction induced by breaking waves on time scales longer than the individual wave period and in this manner, he described the rip current system in the surf zone. Finally, Castelle et al. (2016) classified types of systems of rip currents based on the dominant controlling forcing mechanism into three groups which included: hydrodynamicallycontrolled rips, bathymetrically-controlled rips and boundary-controlled rips.

It should be noted that none of the published analytical models for the rip spacing considered the beach state and variation in rip current types. So, the results of these studies indicated that the distance between channels was generally related to the bed morphology, including the beach slope and the width of surf zone. This study focuses on a simplified analytical model to evaluate the spacing of bathymetrically-controlled rip currents, specifically channel rips. The main purpose of this research is to find a simple and reasonable relationship between the characteristics of the wave, current and bed with the patterns governing the rip currents. Since channel rip currents are relatively stationary over long periods of time, they can be monitored through field measurements of wave and current parameters in the surf zone. On the other hand, given that the calculations and related formulas in analytical model that are presented using the equations of continuity and momentum in accordance with the assumptions and conditions governing the beach, it is easily possible to estimate the distances between channels in this type of rip current system. Hence, the results of this analytical model, acknowledging its simplicity, are practical for beaches susceptible to the formation of these types of rip currents.

In order to investigate the results obtained from this study, the results of numerical model with field observations were compared and then in the next step, results of the analytical model were compared with the results of numerical simulations, calibrated with field studies of other researchers. The study is structured as follows: In section 2, the analytical model, different assumptions in the model and governing equations are described. In section 3 , we present the numerical model results on the rip current system and discuss the results with the analytical model estimations. In section 4 , the results are compared with field observations in two stages and then the results are summarized in section 5 .

\section{The analytical model}

\subsection{Description of the analytical model}

In this paper, it is aimed to calculate the spacing of channel rip currents using a simple analytical model. Therefore, in the first step, it seems necessary to introduce this particular type of rip current before introducing the analytical model. Channel rip currents are the most visible and documented rip current type in the beaches that are usually found on beaches with intermediate beach states (Wright and Short 1984; Brander and Scott 2016). Channel rips are caused by alongshore variation in breaking wave height and gradients of radiation stress due to alongshore variability in bed topography (Bowen 1969). So, the studied model was designed based on an undulating bed so that the rip channels are recognizable. These currents can be stationary in their position for a period of days to even months and typically form during propagation of shore-normal waves (Short and Brander 1999; Winter et al. 2014). For this reason, in analytical model it was assumed that the waves under small angles attack the beach. Finally, the equations of continuity and momentum were used to predict the 


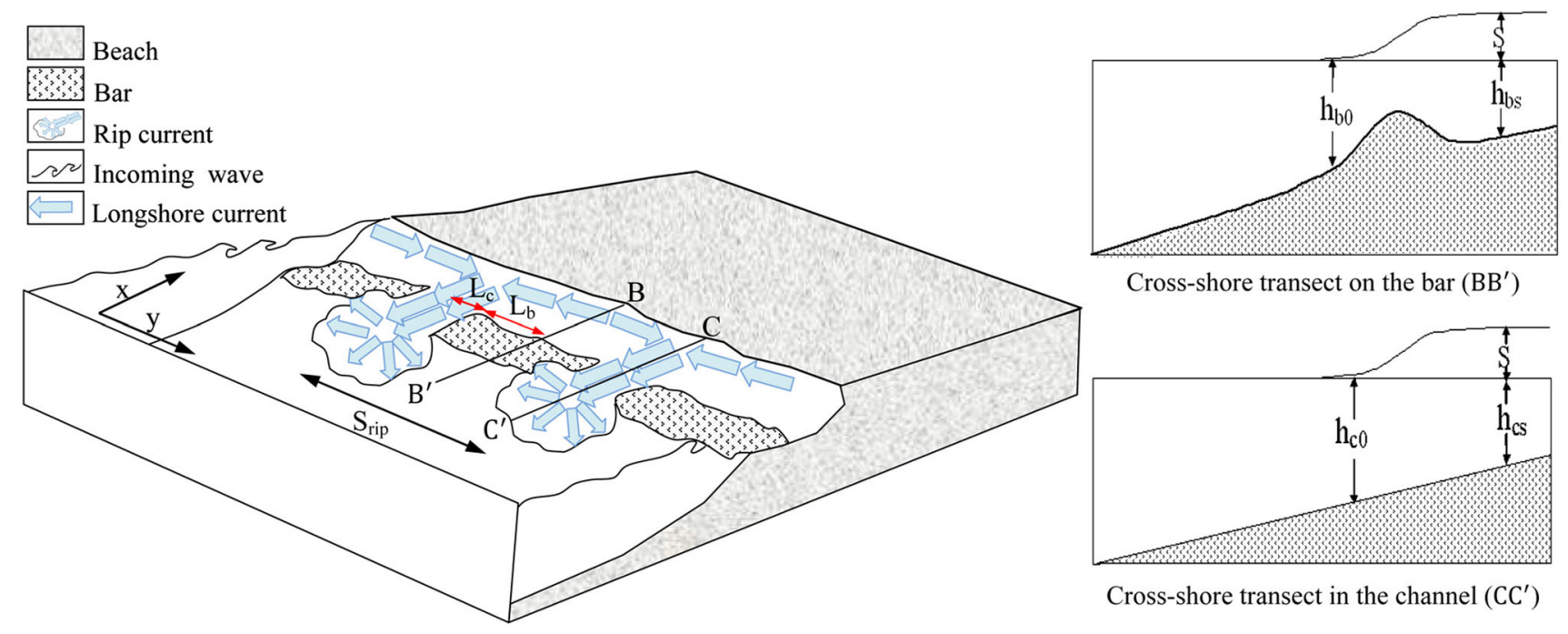

Figure 1. A scheme to represent the rip current system in the analytical model.

spacing of the rip channels in this model. In the model, the coordinate axes are oriented so that the $\mathrm{x}$-axis is perpendicular to the beach and the $\mathrm{y}$-axis is along the beach (figure 1).

\subsection{Simplifications and assumptions in the analytical model}

When the waves approach the beach, they gradually break as a result of encountering the near shore shoals. In this condition, bed unevenness leads to alongshore variations of wave height as a result of breaking of the waves. Longuet-Higgins and Stewart (1964) demonstrated that rip current formation is related to these alongshore variations of wave height that result in alongshore variations in wave-induced momentum flux, termed radiation stress. As a result, near shore circulation cells consisting of rip currents and undertows are created in the beach. It is assumed that the driven undertows caused by the radiation stress and wave setup gradients converge in return to the sea and pass from rip channels. Therefore, in this study, using the theory of Longuet-Higgins and Stewart (1964), an analytical model to estimate the spacing of channel rips based on wave parameters and current is presented.

\subsection{Governing equations in the analytical model}

In order to achieve the objectives of the study, the equations of continuity and momentum in the near shore zone are used in accordance with the following equations

$$
\begin{gathered}
\frac{\partial \bar{\eta}}{\partial t}+\frac{\partial}{\partial x}[(h+\bar{\eta}) u]+\frac{\partial}{\partial y}[(h+\bar{\eta}) v]=0, \\
(h+\bar{\eta})\left(\frac{\partial u}{\partial t}+u \frac{\partial u}{\partial x}+v \frac{\partial u}{\partial y}\right) \\
=-g(h+\bar{\eta}) \frac{\partial \bar{\eta}}{\partial x}+F_{x}-\tau_{x} \\
(h+\bar{\eta})\left(\frac{\partial v}{\partial t}+u \frac{\partial v}{\partial x}+v \frac{\partial v}{\partial y}\right) \\
=-g(h+\bar{\eta}) \frac{\partial \bar{\eta}}{\partial y}+F_{y}-\tau_{y}
\end{gathered}
$$

In the above equations, $u$ and $v$ are the crossshore and alongshore velocity components, respectively in the mean depth and $\eta$ is water level elevation. In other words, $\eta$ is the mean wave setup, which is due to wave breaking. The $F$ is force applied to the water column due to wave action. In order to calculate the spacing of rip channels, momentum equation is considered in the $y$ directions and with regard to model assumptions as $\partial / \partial x \ll \partial / \partial y$, the momentum equation using $F_{y}$ is defined as follows:

$$
F_{y}=-\frac{1}{\rho}\left[\frac{\partial S_{x y}}{\partial x}+\frac{\partial S_{y y}}{\partial y}\right]=-\frac{1}{\rho}\left[\frac{\partial S_{y y}}{\partial y}\right] .
$$

Momentum equation is rewritten then as:

$$
\begin{aligned}
& (h+\bar{\eta}) \frac{\partial v}{\partial t}-(h+\bar{\eta}) v \frac{\partial v}{\partial y} \\
& =-g(h+\bar{\eta}) \frac{\partial \bar{\eta}}{\partial y}-\frac{1}{\rho} \frac{\partial S_{y y}}{\partial y}-\tau_{y} .
\end{aligned}
$$

Assume that this model is investigated in a mean steady condition. 


$$
\begin{aligned}
& \frac{\left[\partial v^{2}(h+\bar{\eta})+g \frac{(h+\bar{\eta})}{2}^{2}\right]}{\partial y} \\
& \quad=g(h+\bar{\eta}) \frac{\partial \bar{\eta}}{\partial y}-\frac{1}{\rho} \frac{\partial S_{y y}}{\partial y}-\tau_{y} .
\end{aligned}
$$

By integrating the above equation along the beach with respect to the information given in figure 1, it can be written as:

$$
\begin{gathered}
\left(h_{b s}+s\right) v_{b s}^{2}+\frac{g}{2}\left(h_{b s}+s\right)^{2}-\left(h_{c s}+s\right) v_{c s}^{2} \\
-\frac{g}{2}\left(h_{c s}+s\right)^{2}-M+S+N=0
\end{gathered}
$$

where

$$
M=\int_{y_{1}}^{y_{2}} g(h+\eta) \frac{\partial \bar{\eta}}{\partial y} .
$$

Noting that the changes of mean sea level along the $\mathrm{y}$-axis are none $(\partial \bar{\eta} / \partial y=0)$, so the $M$ parameter in the above equation can be neglected, and considering that the alongshore current velocity in the channel is zero $\left(v_{c s}=0\right)$, the third term of the above equation is also removed.

In addition, it is assumed that the water depth is the same in almost all areas in onshore zone, in other words, $h_{b s} \cong h_{c s}$ is assumed. On the other hand, in the above relations radiation stress can be written as:

$$
S=\left(\left(S_{y y, b y_{2}}-S_{y y, c y_{1}}\right) / \rho\right) .
$$

As defined by Phillips (1966) in shallow water, regardless of Reynolds stress and using the nondimensional radiation stress $S_{y y}=\frac{1}{2} e\left(1+2 \sin ^{2} \theta\right)$ with $e=\frac{1}{8} \rho g H^{2}$, the radiation stress equation is rewritten as:

$$
S=\frac{1}{16} g\left(1+2 \sin ^{2} \theta\right)\left(H_{b}^{2}-H_{c}^{2}\right) .
$$

However, using the definition of the seabed shear stress $\tau_{y}=\rho C_{f}\langle|\vec{u}|\rangle v$, where $C_{f}$ is the bottom friction coefficient and $\rho$ is the density of sea water (Pingree and Griffiths 1979), alongshore and crossshore velocity components are defined as follows:

$$
\begin{aligned}
& u=\bar{u}+u_{0} \cos (\omega t) \cos \theta, \\
& v=\bar{v}+u_{0} \cos (\omega t) \sin \theta .
\end{aligned}
$$

In this relation, we ignore the mean alongshore current velocity against the mean cross-shore current velocity. Indeed, $\bar{v}=0$. Therefore, $\tau_{y}$ is defined as follows:

$$
\begin{aligned}
\tau_{y}= & \rho C_{f}\left\langle\left(\bar{u}^{2}+2 \bar{u} u_{0} \cos \omega t \cos \theta+u_{0}^{2} \cos ^{2}(\omega t) \cos ^{2} \theta\right.\right. \\
& \left.\left.+u_{0}^{2} \cos ^{2}(\omega t) \sin ^{2} \theta\right)^{\frac{1}{2}} u_{0} \cos (\omega t) \sin \theta\right\rangle
\end{aligned}
$$

Assuming that waves approach the beach with small angles $(\cos \theta \cong 1)$ and notice that $u_{0} \ll \bar{u}$, therefore, $u_{0} \cos \theta \ll \bar{u}$. Also, for small angles $(\sin \theta<1)$, so $u_{0} \sin \theta \ll \bar{u}$. Therefore, $\tau_{y}$ is rewritten as:

$$
\tau_{y}=\rho C_{f}\langle\bar{u} \cdot \bar{u}\rangle .
$$

Also, in equation (7), parameter $N$ is defined as follows:

$$
\begin{aligned}
N & =\int_{y_{1}}^{y_{2}} \tau_{y} d y=\int_{y_{1}}^{y_{2}} \rho C_{f} \bar{u}^{2} d y \\
& =\rho C_{f}\left(\bar{u}_{b}^{2}-\bar{u}_{c}^{2}\right)\left(y_{2}-y_{1}\right) .
\end{aligned}
$$

In the above relation, $\left(y_{2}-y_{1}\right)$ is equal to spacing of the rip channels and indices $b$ and $c$ show the position of the bar and the channel, respectively (figure 3 ). Hence, the parameter $N$ is defined as follows:

$$
N=\rho C_{f}\left(\frac{u_{b}+u_{c}}{2}\right)^{2}\left(L_{b}+L_{c}\right) .
$$

Inserting equation (12) into equation (7)

$$
\begin{gathered}
\left(h_{b s}+s\right) v_{b s}{ }^{2}+\frac{1}{16} g\left(1+2 \sin ^{2} \theta\right)\left(H_{b}{ }^{2}-H_{c}{ }^{2}\right) \\
+\rho C_{f}\left(\frac{u_{b}+u_{c}}{2}\right)^{2}\left(L_{b}+L_{c}\right)=0 .
\end{gathered}
$$

Therefore, spacing of the rip channels is defined as follows:

$$
S_{\text {rip }}=2 \frac{\left(h_{b s}+s\right) v_{b s}^{2}+\frac{1}{16} g\left(1+2 \sin ^{2} \theta\right)\left(H_{b}{ }^{2}-H_{c}{ }^{2}\right)}{\rho C_{f}\left(\frac{u_{b}+u_{c}}{2}\right)^{2}} .
$$

The rip current spacing can be rewritten, using continuity equation in cross-shore direction according to following relations in steady state

$$
\frac{\partial}{\partial x}[(\bar{\eta}+h) u]=0 .
$$

The integrated form of equation (15) in crossshore direction is as follows:

$$
\left(h_{b s}+s\right)=\frac{u_{b 0}}{u_{b s}} h_{b 0} .
$$


Table 1. Variable conditions governing the rip currents system in the model

\begin{tabular}{|c|c|c|c|c|c|c|c|}
\hline Case & Variable conditions & $\mathrm{H}(\mathrm{m})$ & $\mathrm{T}(\mathrm{s})$ & $\theta\left({ }^{\circ}\right)$ & $\mathrm{d} 50(\mathrm{~mm})$ & $C f(\mathrm{~m})$ & $\tan \theta$ \\
\hline \multicolumn{8}{|c|}{ Wave conditions } \\
\hline $\mathrm{W} 1$ & Wave height & $1,1.5,2.2$ & 5 & 0 & 0.2 & 0.04 & 0.0075 \\
\hline $\mathrm{W} 2$ & Wave period & 1.5 & $5,7,9$ & 0 & 0.2 & 0.04 & 0.0075 \\
\hline W3 & Wave angle & 1.5 & 5 & $0,20,40,90$ & 0.2 & 0.04 & 0.0075 \\
\hline \multicolumn{8}{|c|}{ Bed conditions } \\
\hline B4 & Sediments size & 1.5 & $5 \mathrm{~s}$ & 0 & $0.1,0.2$ & 0.04 & 0.0075 \\
\hline B5 & Friction coefficient & 1.5 & $5 \mathrm{~s}$ & 0 & 0.2 & $0.04,0.02$ & 0.0075 \\
\hline B6 & Bed slope & 1.5 & $5 \mathrm{~s}$ & 0 & 0.2 & 0.04 & $0.0075,0.01$ \\
\hline
\end{tabular}

Table 2. Model parameters

\begin{tabular}{lll}
\hline Different parameters & Initial planar beach & Longshore barred beach \\
\hline Computational domain size & $700 \mathrm{~m} \times 1500 \mathrm{~m}$ & $500 \mathrm{~m} \times 800 \mathrm{~m}$ \\
Beach slope & 0.0075 & Variable \\
Elements, nodes & 2491,1325 & 1545,841 \\
Grid spacing & $15-30 \mathrm{~m}$ & $5-15 \mathrm{~m}$ \\
Time step, simulation time & $1 \mathrm{~s}, 2$ months & $1 \mathrm{~s}, 1$ month \\
\hline
\end{tabular}

The rip current spacing is then obtained by substituting (16) into equation (14)

$$
S_{\text {rip }}=2 \frac{\frac{u_{b 0}}{u_{b s}} h_{b 0} v_{b s}{ }^{2}+\frac{1}{16} g\left(1+2 \sin ^{2} \theta\right)\left(H_{b}^{2}-H_{c}^{2}\right)}{\rho C_{f}\left(\frac{u_{b}+u_{c}}{2}\right)^{2}} .
$$

\section{Numerical model}

MIKE $21 / 3$ is a comprehensive modeling system for two and three dimension free-surface flows. This modeling system is appropriate for simulations of related phenomena in lakes, estuaries, bays, and coastal seas, and is designed by the Danish Hydraulic Institute. In this study, we used MIKE 21/3 Coupled FM Model for morphological assessment of the near shore zone in various hydrodynamic conditions. The mutual interaction between waves and currents was investigated using a dynamic coupling between the hydrodynamic module, the spectral wave module and the sand transport module (DHI 2007).

\subsection{Design of rip current system and model setup}

In this paper, the rip spacing was studied using modeling of rip current system with alongshore bar. First, an initial planar beach is exposed to waves with an average height of $1.5 \mathrm{~m}$ for two months. In the next step, different hydrodynamic and morphodynamic conditions were implemented to the
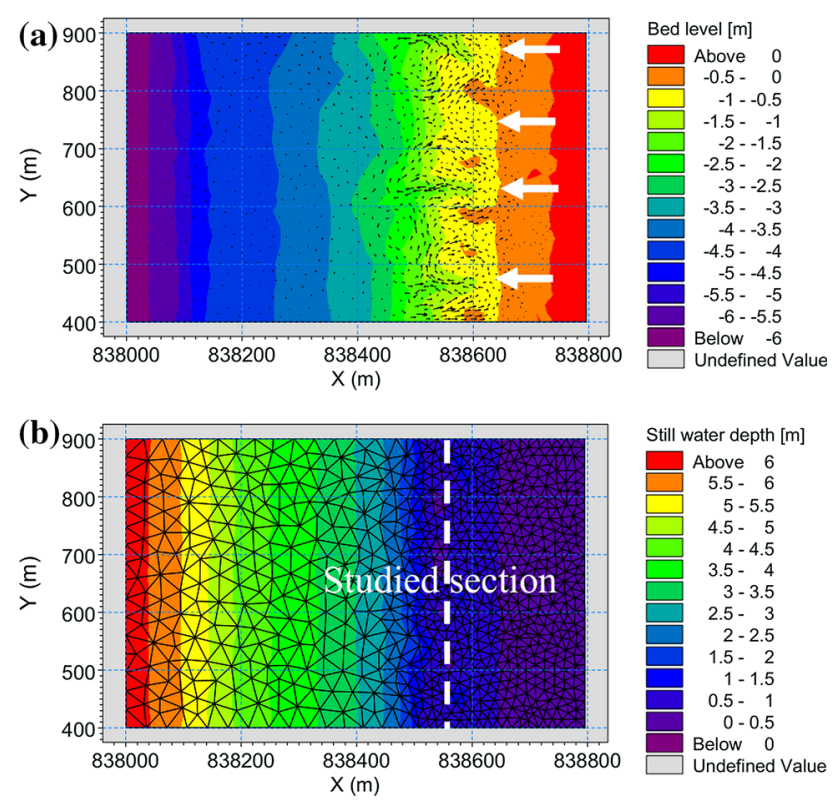

Figure 2. (a) Initial bathymetry and (b) model computational domain with studied section.

created bed with alongshore bar for one month, according to the conditions governing the rip current system in the intermediate beaches (table 1). In the hydrodynamic module for the bottom roughness, constant Manning's coefficient of $32 \mathrm{~m}^{1 / 3} / \mathrm{s}$ has been used. Also, the horizontal eddy viscosity is considered to be $0.28 \mathrm{~m}^{2} / \mathrm{s}$ based on the Smagorinsky formulation. In the sand transport module, the diameter of the non-cohesive sediments is variable and the porosity of the bottom 
sediment is considered equal to 0.4. In the spectral wave module, wave breaking formulation is done based on the formulation of Battjes and Janssen (1978). Other details related to the model set up processes in two different steps of implementing the model, are described in table 2 . Figure 2 shows initial bathymetry with alongshore bar, model computational domain and the studied section.

\subsection{Results of numerical simulation}

In this study, in order to investigate the effect of changing wave and bed parameters on the rip current system, the results of numerical modeling have been extracted in the form of cross-shore bed profiles (to study the amount of changes in surf zone width) and longshore bed profiles (to investigate the rip spacing) (figures 3-5).
The numerical model results show that with increasing wave height, the longshore bar is transported to the farther away regions from the coastline, and as a result, the surf zone width increases (figure 3). On the other hand, according to Hino (1974) and other researchers, the surf zone width $\left(x_{b}\right)$ is proportional to the distance between the rip channels. Therefore, it is expected that the distance between the rip channels increases as the wave height increases. Investigating the longshore bed profile by removing the third channel of waves higher than one meter, 10 days later, confirms this subject (figure 4). In this situation, the beach state gradually changes from rhythmic bar and beach (RBB) to longshore bar and trough (LBT) as shown in figure 6 .

Therefore, the numerical model results prove that with increasing the wave height by changing the shape of the bed (increasing the width of the

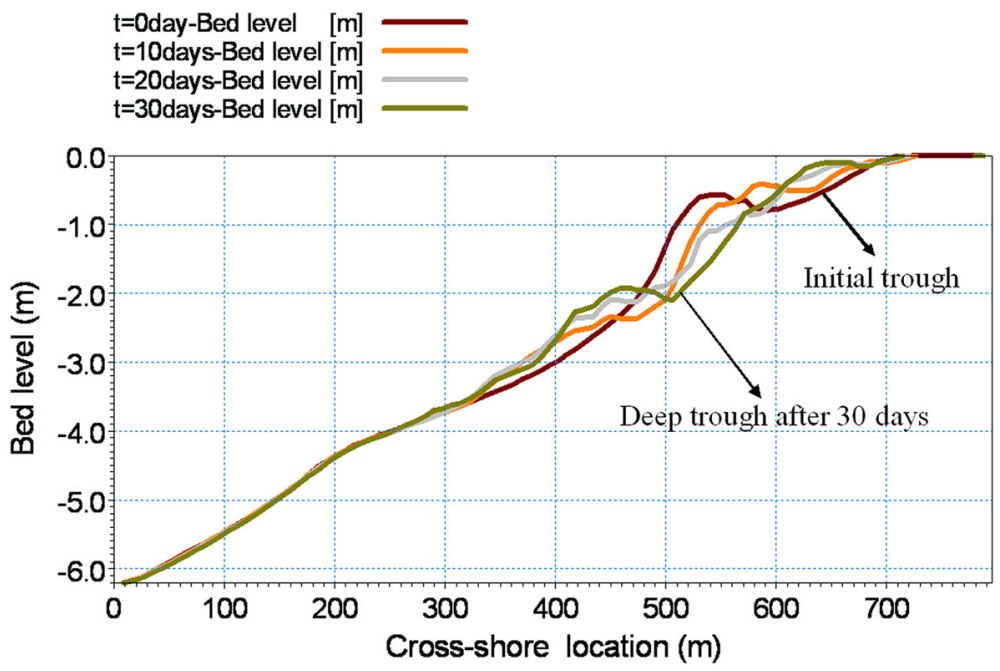

Figure 3. The profile of bed level passing over the bar $(y=580 \mathrm{~m})$ in different times.

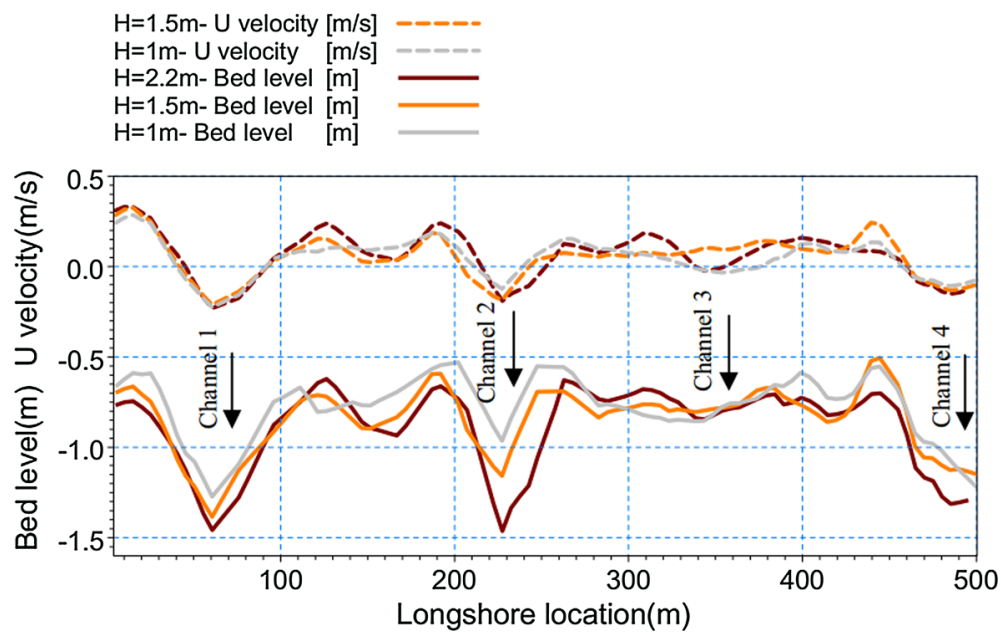

Figure 4. Part of longshore section passing over the bar and channels after 10 days in W1 case (see table 1). 


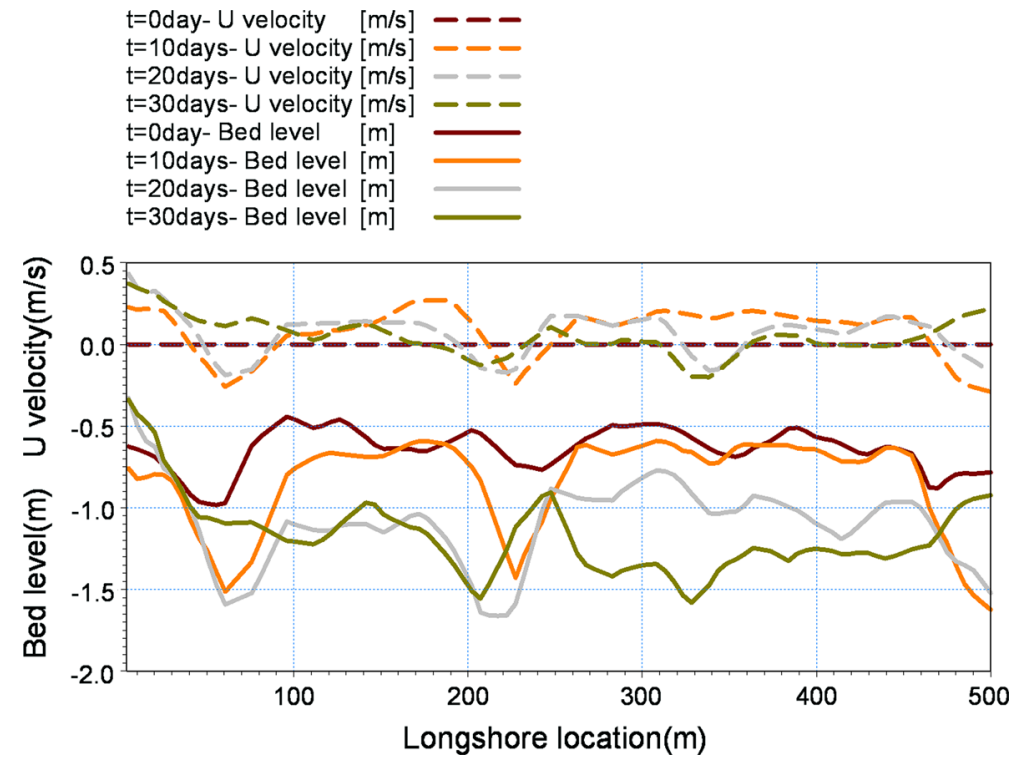

Figure 5. Part of the longshore section passing over the bar and channels with gd $=0.1 \mathrm{~mm}$ in different days.
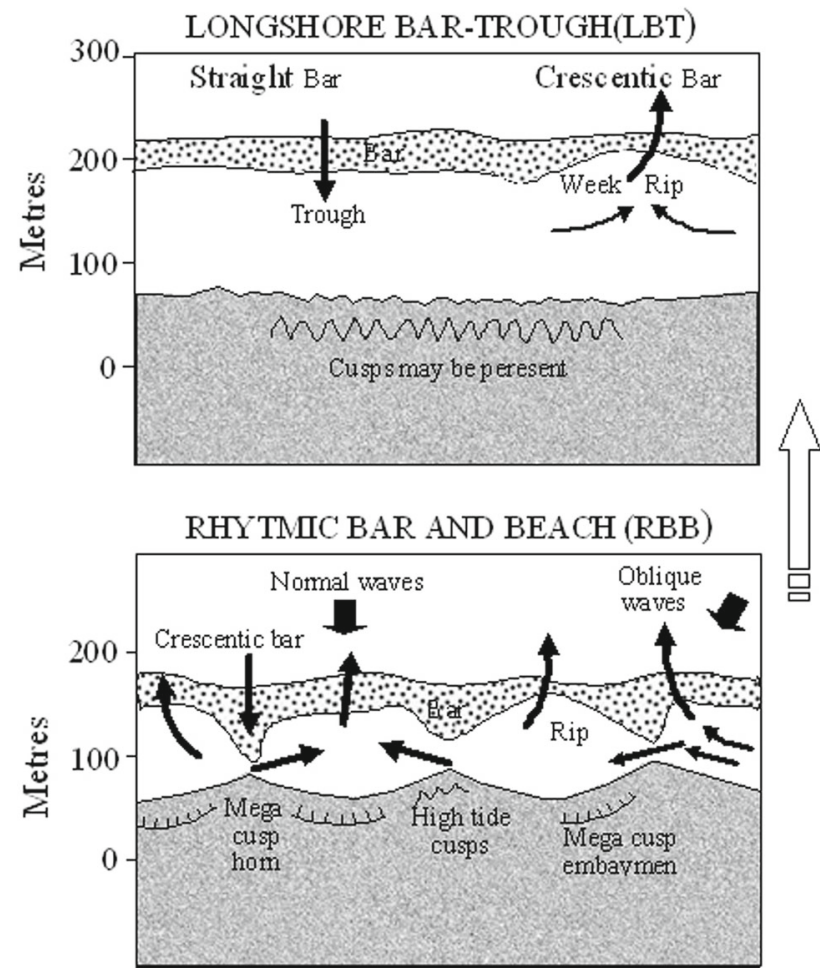

Figure 6. Scheme of intermediate beaches (Wright and Short 1984).

surf zone), the spacing of channels will increase with time. Thus, the simultaneous effect of the hydrodynamic conditions and bed morphology are completely visible on rip spacing. This result is also confirmed by other investigations of the rip current systems (figure 7).

To investigate the interaction of hydrodynamic conditions and bed morphology and its effects on the spacing of channel rip currents, it seems necessary to analyze and evaluate the effective factors on fitting of rip currents as a result of changes in bed conditions. For this purpose, in this paper, the rip-fit parameter that was introduced by Brander (1996) studies for each item listed in table 1 was investigated.

$$
R f=M-\frac{O}{A r},
$$

where $M$ is the morphological rip area, $O$ is the overbank rip area and $A r=M+O$.

When the rip currents are weak compared to the size of their channel, in this case $R f>1$ and rips are underfit. In this case, the rip currents will not be able to dig their channel and even create channels through deposition of sediment fill. According to the field studies conducted by Brander (1996) under the effects of uniform falling waves, these currents remain fixed in their places until they are filled with sediment and this situation may continue for several weeks. Accumulation of sediments caused by the underfit in the first and fourth channels after 30 days is shown in figure 5. According to Brander (1996), the overfit occurs when the width of rip current is greater than its channel. In this case, $R f<1$ and the rip current is strong and in order to fit between the current and dominant morphology of the region, the size of the rip channel will increase as a result of erosion Short (1999). Figure 8 shows the scatter plots related to the dimensionless parameter $\left(H_{b 0} / h_{c}\right)$ vs. the rip-fit parameter $(R f)$ in different situations of wave and bed. The investigation of different plots 

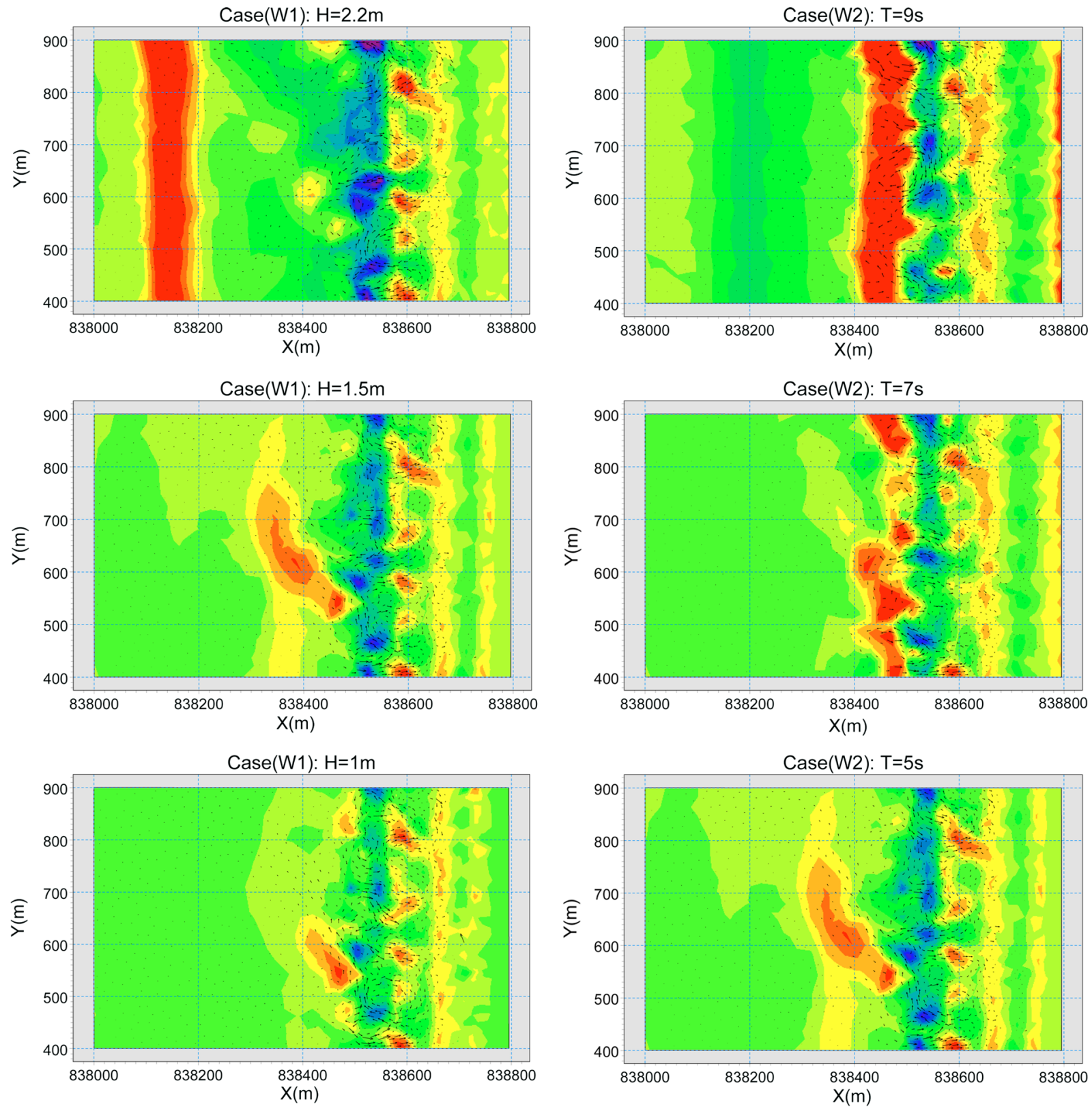

Bed level change[m]

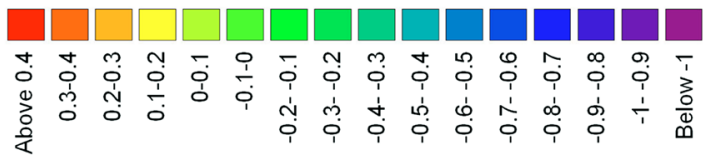

Figure 7. The pattern of bed level variation after 10 days for different cases (see table 1).

related to this figure indicates that if ratio of wave height over the bar against the water depth in the channel increases, $R f$ decreases. Also, in this situation if the dimensionless parameter $\left(H_{b 0} / h_{c}\right)$ exceeds a certain amount, then overfit occurs and vice versa. This is not only a function of changes of wave height, but also any changes in wave and bed conditions that occur. Thus, it can be concluded that dimensionless parameter $\left(H_{b 0} / h_{c}\right)$ represents the rip current situation in terms of stability and instability of the beach.

\section{Comparison with field data}

Many studies were carried out in the past by researchers such as Bowen and Inman (1969), Dean (1973), Hino (1974), Sasaki and Horikawa 

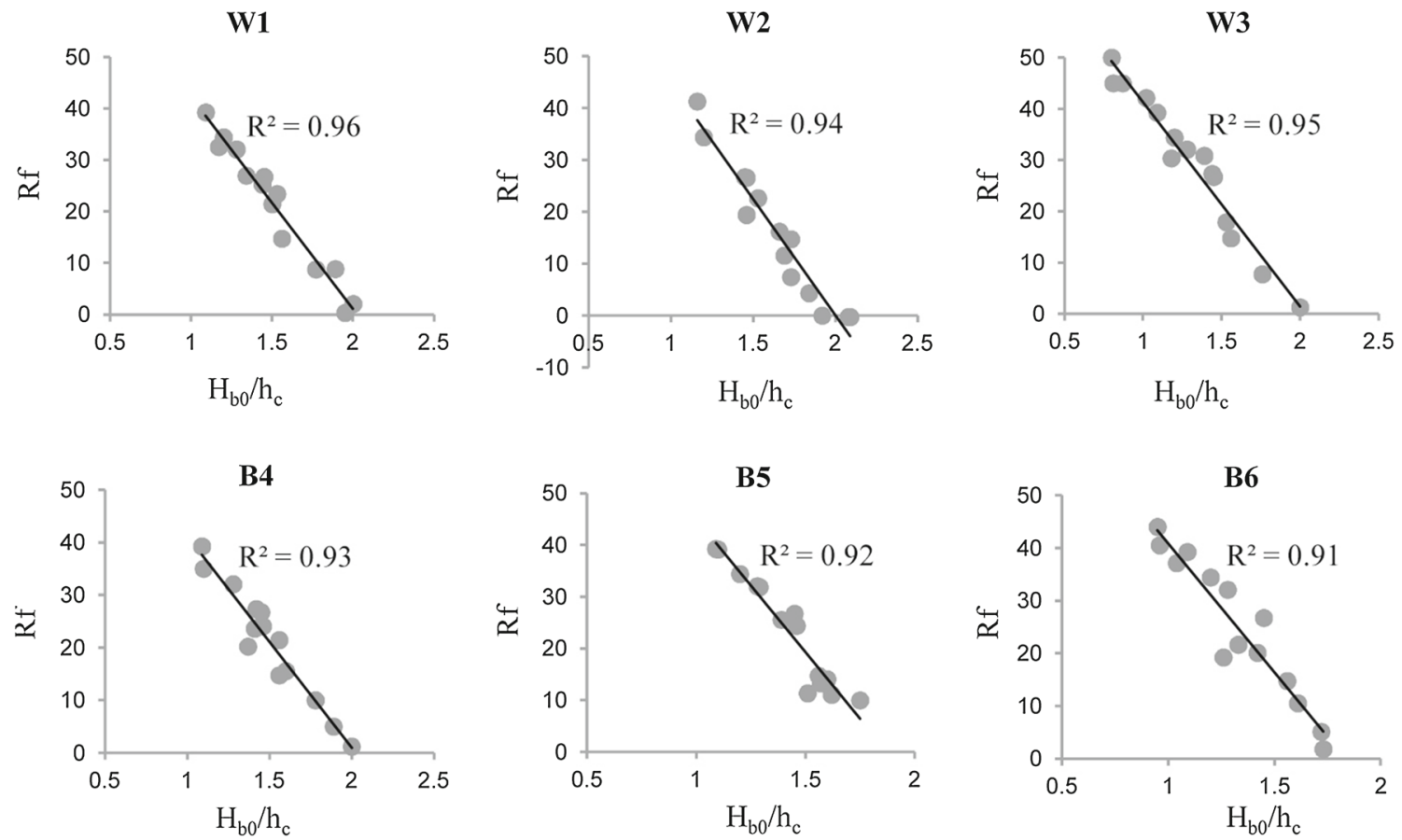

Figure 8. Scatter plots to represent the relation between the dimensionless parameter $\left(H_{b 0} / h_{c}\right)$ and the rip-fit parameter $(R f)$ in different conditions of wave and bed (see table 1$)$.
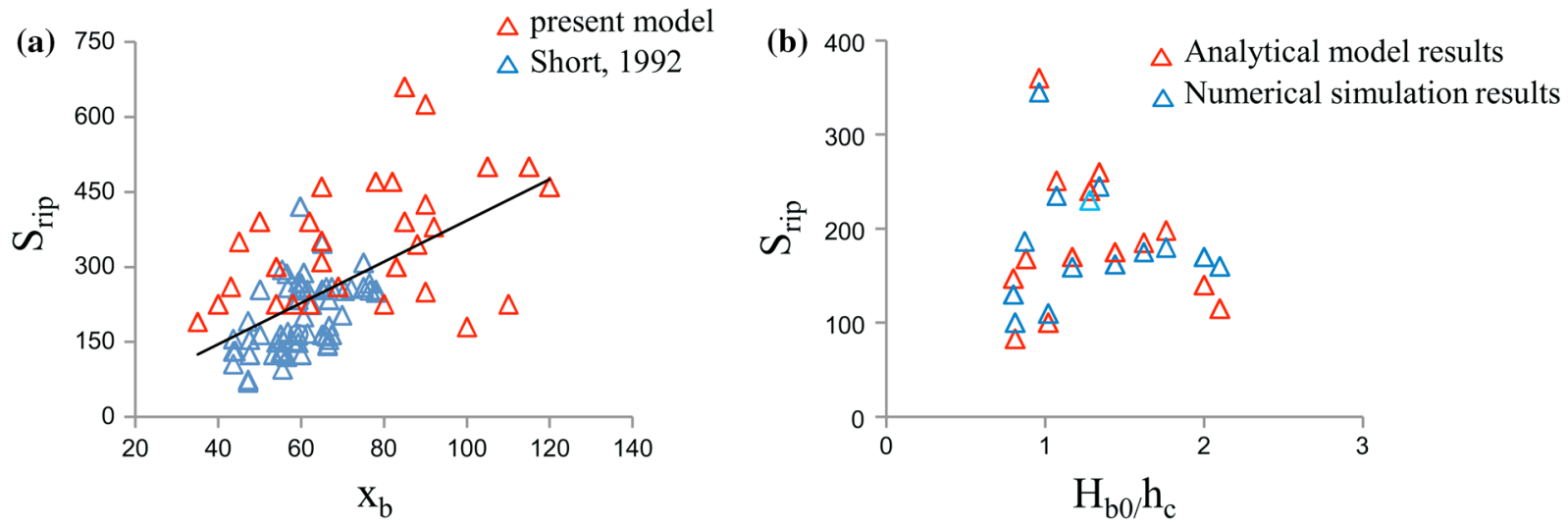

Figure 9. Scatter plots representing (a) the relation between the rip current spacing $\left(S_{\text {rip }}\right)$ and the surf zone widths $\left(x_{b}\right)$ in present numerical study and the field observations (Huntley and Short 1992). (b) Comparison of analytical and numerical results.

(1978), Short (1985) and Huntley and Short (1992) regarding the relationship between rip spacing $\left(S_{\text {rip }}\right)$ and width of the surf zone $\left(x_{b}\right)$. These researchers estimated that spacing of rip channels was approximately $1.5-8$ times the surf zone width using various methods such as methods of analysis and field studies. This study focused on the study of a particular type of rip currents as channel rip that are mainly formed in the intermediate beaches. Thus, to validate the results of the present study, in the first step, the results of numerical simulation were compared with results of field studies conducted by Short (1985) in the intermediate beaches. Figure 9(a) shows good agreement between results of numerical simulation with the obtained results by Huntley and Short (1992) in the same period. In the next step, analytical model results were compared with the results of numerical simulations. According to figure 9(b), these results are consistent in majority of the cases.

After the validation of the results of the numerical study, the results of analytical model were compared with the results of numerical simulations. According to figure 9(b), this comparison shows good agreement between the two, in most cases. 


\section{Discussion and conclusions}

In this study, a simplified analytical model was presented for intermediate beach using the equations of continuity and momentum. Using this model, if the hydrodynamic conditions governing the beach are available, the spacing of channel rips that are common rips on intermediate beach, can be estimated. Also, the influencing factors of rip spacing in different conditions of wave and bed were studied by investigating the cross and longshore profiles using numerical simulations. Then, the obtained overall results were compared with reported field results of other related studies, that confirmed the findings of the present study. The results of this research show that when the ratio of the wave height before approaching the bar $\left(H_{b 0}\right)$ to the channel depth $\left(h_{c}\right)$ exceeds a certain amount $\left(H_{b 0} / h_{c} \geq 2\right)$, the results of analytical model and numerical simulation gradually depart from each other.

Based on the research findings presented by Brander (1996) and also the results of the numerical simulation in this study, it is expected that if the wave height increases, the rip spacing increases until the rip currents become stable or infinitely long and the beach will reach to a dissipative state. While the analytical model is based on intermediate beaches with long shore bar and rip channels. This not only depends on the wave height governing the beach, but also in general is related to the hydrodynamic and morphodynamic conditions governing the surf zone simultaneously. According to the results of this study, by changes in various parameters of wave and bed, the ratio of $H_{b 0} / h_{c}$ also varies. On the other hand, when ratio of the wave height before approaching the bar $\left(H_{b 0}\right)$ to the channel depth $\left(h_{c}\right)$ exceeds a certain amount $\left(H_{b 0} / h_{c} \geq 2\right)$, we will be faced with a reduction in the ripfit parameter $(R f)$ and when $R f<1$, then the rip currents reach the overfitted case. In other words, in this study dimensionless parameter $\left(H_{b 0} / h_{c}\right)$ is a simple, accessible and important parameter in determining the stability or instability of channel rips on intermediate beaches introduced.

\section{Acknowledgements}

The authors would like to appreciate Dr Malekzadeh and Dr Karami for their constructive comments and useful suggestions.

\section{References}

Battjes J A and Janssen J P F M 1978 Energy loss and setup due to breaking of random waves; Proc. 16th Int. Conf. Coastal Engineering, ASCE, pp. 569-587.

Bowen A J 1969 Rip currents 1: Theoretical investigations; J. Geophys. Res. 74 5438-5478.

Bowen A J and Inman D L 1969 Rip currents 2: Laboratory and field observations; J. Geophys. Res. 74 54795490.

Brander R W 1996 Field Observations on the Morphodynamics of Rip Currents; Unpubl. PhD thesis, Department of Geography, University of Sydney, 240p.

Brander R W 1999 Field observations on the morphodynamic evolution of a low-energy rip current system; Marine Geol. 157(3-4) 199-217.

Brander R W and Scott T 2016 Science of the rip current hazard; In: The Science of Beach Lifeguarding: Principles and Practice (eds) Tipton M, Wooler A and Reilly T, CRC Press, pp. 67-86.

Castelle B, Scott T, Brander R W and McCarroll R J 2016 Rip current types, circulation and hazard; Earth Sci. Rev. $1631-21$.

Dean R G 1973 Heuristic models of sand transport in the surf zone; Proc. Conf. Engineering Dynamics in the Surf Zone, Sydney, N.S.W, pp. 208-214.

Deigaard R, Dronen N, Fredsoe J, Jensen J H and Jorgensen M P 1999 A morphological stability analysis for a long straight barred coast; Coast. Eng. 36 171-195.

DHI software 2007 MIKE 21 user guide manual; Danish Hydraulic Institute.

Eliot I 1973 The persistence of rip current patterns on sandy beaches; Proc. $1^{\text {st }}$ Aus. Conf. Coast. Eng., pp. 29-34.

Falqués A, Coco G and Huntley D A 2000 A mechanism for the generation of wave-driven rhythmic patterns in the surf zone; J. Geophys. Res. 105 24,071-24,087.

Hino M 1974 Theory on the formation of rip-current and cuspidal coast; Proc. 14 th Int. Conf. Coast. Eng., pp. 901919.

Holman R A, Symonds G, Thornton E B and Ranasinghe R 2006 Rip spacing and persistence on an embayed beach; J. Geophys. Res. 111 C01006, https://doi.org/10.1029/ 2005JC002965.

Huntley D A and Short A D 1992 On the spacing between observed rip currents; Coast. Eng. 17 211-225.

Iwata N 1976 Rip current spacing; J. Oceanogr. Soc. Japan 32 1-10.

Longuet-Higgins M S and Stewart R W 1964 Radiation stress in water waves: A physical discussion, with applications; Deep-Sea Res. Oceanogr. Abstr. 11(4) 529-562, https:// doi.org/10.1016/0011-7471(64)90001-4.

Osaisai E F 2013 An analytical model of the rip current flow; Int. J. Comp. Eng. Res. 3 1-12.

Phillips O M 1966 The Dynamics of the Upper Ocean; 2nd edn, Cambridge University Press, Cambridge.

Pingree R D and Griffiths D K 1979 Sand transport paths around the British Isles resulting from the M2 and M4 tidal interactions; J. Mar. Biol. Assoc. 59 497513.

Sasaki T and Horikawa K 1978 Observation of near shore current and edge waves; Proc. 16th Int. Conf. Coast. Eng., $A S C E$, pp. 791-805. 
Short A D 1985 Rip current type, spacing and persistence, Narrabeen Beach, Australia; Marine Geol. 65 47-71.

Short A D 1999 Beach and Shore Face Morphodynamics; Wiley, Chichester, 379p.

Short A D and Brander R W 1999 Regional variations in rip density; J. Coast. Res. 15(3) 813-822.

Symonds G, Holman R A and Bruno B 1997 Rip currents; In: Coastal Dynamics (ed.) Thornton E B, Am. Soc. Civ. Eng., Reston, pp. 584593.

Tiessen M C H, Van Leeuwen S M, Calvete D and Dodd N 2010 Field test of a linear stability model for crescentic sandbar; Coast. Eng. 57 41-51.

Corresponding editor: D SHANKAR
Turner I L, Whyte D, Ruessink B G and Ranasinghe R 2007 Observations of rip spacing, persistence and mobility at a long, straight coastline; Mar. Geol. 236 209-221.

Whyte D, Turner I L and Ranasinghe R 2005 Rip characterization on the Gold Coast, Australia: An analysis using coastal imaging techniques; Proc. 17th Conf. Aust. Coast. Ocean Eng., pp. 233-238.

Winter G, van Dongeren A R, de Schipper M A and van Thiel de Vries J S M 2014 Rip currents under obliquely incident wind waves and tidal longshore currents; Coast. Eng. 89 106-119.

Wright L D and Short A D 1984 Morphodynamic variability of surf zones and beaches: A synthesis; Marine Geol. 56 93-118. 